\begin{tabular}{|c|c|c|}
\hline 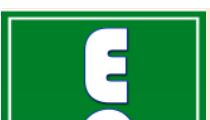 & $\begin{array}{l}\text { International Journal of Current Research in } \\
\text { Biosciences and Plant Biology }\end{array}$ & $=$ \\
\hline & Volume 6 • Number 1 (January-2019) • ISSN: 2349-8080 (Online) & $\begin{array}{l}0 \\
-69\end{array}$ \\
\hline $\begin{array}{l}\text { EXCELLEN } \\
\text { PUBLISHERS }\end{array}$ & Journal homepage: $\underline{w w w . i j c r b p . c o m}$ & \\
\hline
\end{tabular}

\title{
Antidiabetic effect of Afromomum meleguata ethanolic seed extract on streptozotocin induced diabetic Wistar rats
}

\author{
R. U. Ukpanukpong ${ }^{* 1}$, D. O. Otu ${ }^{1}$, O. E. Olarinde ${ }^{2}$, R. O. Fafioye ${ }^{2}$, \\ B. E. Ukwuondi ${ }^{1}$ and P. O. Igbineweka ${ }^{1}$ \\ ${ }^{1}$ Department of Biochemistry, University of Calabar, Calabar-Nigeria. \\ ${ }^{2}$ Department of Chemical Sciences, Joseph Ayo Babalola University, Osun State -Nigeria \\ *Corresponding author; e-mail: richard2012ukpanukpong@gmail.com
}

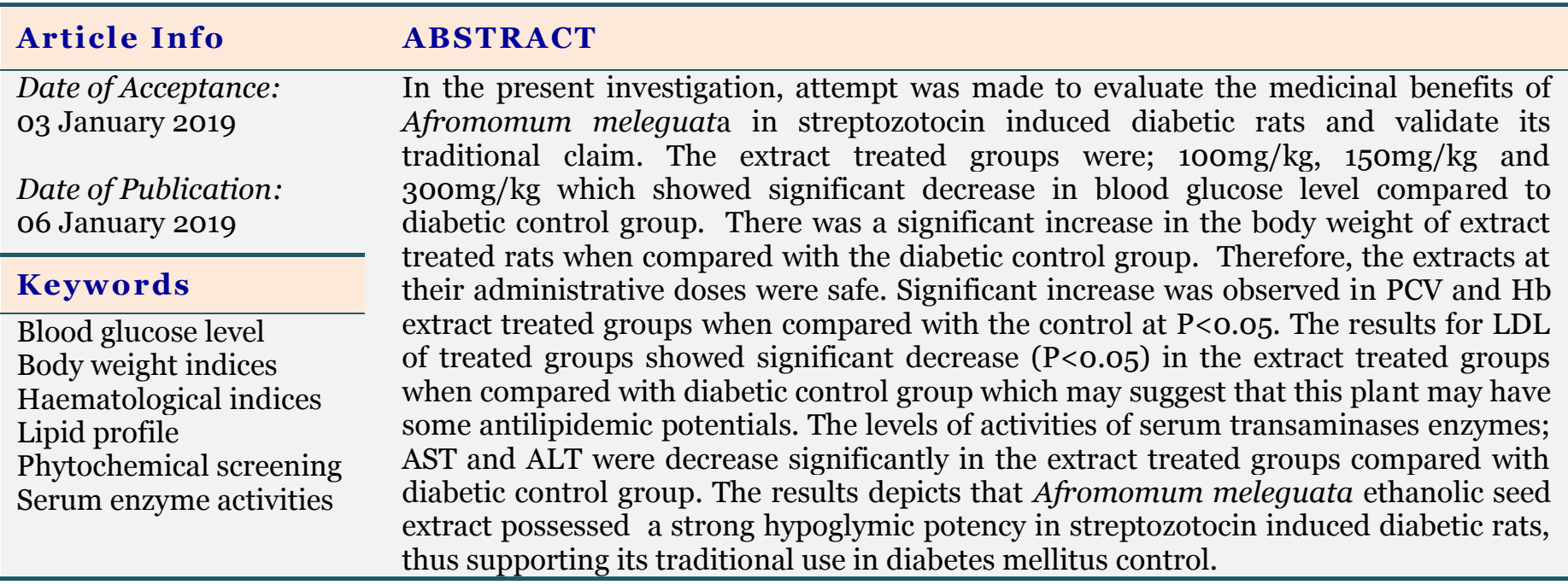

\section{Introduction}

Medicinal plants are those plants which contain substances that are used for the treatment or prevention of diseases and other health disorders in human body. Herbal medicines contain bioactive substances which sometimes have adverse effect on body organs when taken in high concentration (Bent and Ko, 2004). The most important of these substances are the alkaloid, fixed oil, essential oil, tannins, resins, etc. It is obvious that some negative results obtained in the use of medicinal plants are basically due to overdose and lack of pharmacodynamics of most plants. This is so because, many medicinal agent which is administered relatively high doses inhibit most biochemical activities in the body (Sharma, 1986). According to (WHO, 1983), developing nations are more interested in the use of traditional indigenous herbal plants in implementing their Primary Health Care (PHC) programmes than orthodox drugs. The common practice is the use of bark, roots and sometimes both. Herbs were described as natural distribution 
on the earth surface by nature according to the needs of the people living therein (Kafaru 1985). Many plants have been discovered to be of medicinal value (Sofowora, 1982). Nigeria have not realized the use of nature bountiful gift such as leaves, roots and bark for the prevention and cure of ailments (Olapode, 2002). This negligence of herbs is as a result of lack of knowledge identification and therapeutic efficacy but efforts are now geared towards putting an end to deforestation, excessive bush burning and save the greenery. The medicinal plants are more accessible to most of the population in the third world (UNESCO, 1976). There is an acceptance promising potential of medicinal plants used in various traditions, complementary and serving as an alternative means of treatment/management of various diseases (Sher, 2009).

Diabetes is a chronic disease that requires continuous medical care and patient healthy life style and education to prevent acute complications and reduce the risk of long term effects. Diabetes's management is to achieve and maintain blood glucose level and reduce the risk of long-term complications. Glycemic control is a medical term referring to the typical levels of blood sugar (glucose) in a person with diabetes mellitus. Many studies have shown that modern management with intensive glycemic control can limit, delayed or even prevent the chronic complications of diabetes (Tarnow et al., 2008). However, this intensive diabetes treatment could be associated with an increased risk of hypoglycemia, particularly in patients with type 1 diabetes mellitus and patients with longstanding insulin treated type 2 diabetes mellitus. Hypoglycemia is a true medical emergency which requires prompt diagnosis and treatment as to prevent organ and brain damage. The spectrum of symptoms depends on duration and severity of hypoglycemia and varied from autonomic activation to behavioral changes to altered cognitive function to seizures or coma. The short and long term complications include neurological damage, trauma, cardiovascular events and death (Adams, 2008).

\section{Materials and methods}

Experimental animals: Adult sixty (60) female albino rats weighing between 120-130g were purchased from a disease free stock of the
University of Ibadan, Nigeria and used for the study. The rats were randomly assigned on the basis of their weight into six study groups of eight (8) rats each. Normal feeds and tap water were given to the rats ad-libitum and food and water intake were noted. They were kept in plastic cages of 8 rats per cage, placed in a well ventilated animal room of Joseph Ayo Babalola University at normal temperature of $30-35^{\circ} \mathrm{C}$. The cages were cleaned daily and the rats were treated according to the international guidelines for the care and use of laboratory animals (NIH, 2008). The animals were allowed for two weeks of acclimatization and their weights were measured before treatment commenced.

Chemicals: Streptozotocin, chloroform, ethanol and other chemicals were obtained fromFam-lab Nigeria Limited and Lixok-k chemicals, Akure respectively. Alanine transaminase (ALT), Aspartate transaminase (AST), Serum albumin were obtained from Randox Laboratories Limited, UK. Johnson one touch glucometer kit was purchased from De-shalom pharmacy, Ilesa, Osun State, Nigeria. All other chemicals used were of analytical grade. De-ionised and distilled water was also used during the experimental process.

Source of drug: Insulin injection (Randox laboratories, UK) marketed by May and Baker, was obtained from a registered pharmacist in Deshalom pharmacy, Ilesa, Osun State, Nigeria and used for the study.

Plant materials and identification: The fresh Afromomum meleguata (Alligator pepper) seeds were obtained from alligator pepper farm in IkejiArakeji plantation, Osun State, Nigeria. The plant samples were taken to the department of Botany, Obafemi Awolowo University (O.A.U) for identification and authentication.

\section{Preparation of plant extracts}

Afromomum meleguata seeds were sorted out, washed to remove dirts and dust particles and air dried under shade for 4 weeks. The dried materials were homogenized using mechanical grinder and weighed in a weighing balance. The powder form was kept in airtight container and stored at $4^{\circ} \mathrm{C}$ until when needed for further analysis. 


\section{Extraction procedures}

Ethanolic extraction: $100 \mathrm{~g}$ of the powdered seed extract was soaked in $98 \%$ of ethanol in $200 \mathrm{ml}$ at room temperature for 72 hours after which the mixture was filtered. The filtrate was placed in centrifuge at 3000 orpm for 30 minutes. The centrifuged sample formed 2 layers; the upper layer was then poured inside another beaker. It was boiled at a very high temperature using a water bath. During the boiling process, it was observed that the sample formed some crystal structure in a foaming form. The resulting filtrate was air-dried at room temperature into Petri dishes. The residue obtained was weighed and kept in air-tight container at $4^{\circ} \mathrm{C}$. Percentage yield was determined from the weight of the dried sample.

\section{Phytochemical screening of plant extract:} Basic phytochemical screening is the method employed to test the presence of certain biologically active compounds in plants e.g. tannins, saponins, antraquinone, flavonoids, cardiac glycosides, steroids, phenolics, cardenolides and denolides. The methods are as follows (A.O.A.C, 2001).

Animal maintenance: The rats were kept in wooden cages barred with steel nets and housed in an environmentally controlled room temperature: $\quad 30.0 \pm 0.6^{\circ} \mathrm{C}, \quad 50-60 \%$ relative humidity with a 12 hour day and night cycle and they were constantly fed and supplied with water. Their surroundings were also cleaned to maintain proper hygiene. The animals had free access to food and water and were treated according to the international guidelines for the care and use of laboratory animals (NIH, 1985). The animals were allowed to acclimatize for two weeks before commencement of the practical.

Induction of diabetes: Diabetes mellitus was induced by single intraperitoneal dose of $60 \mathrm{mg} / \mathrm{kg}$ of streptozotocin (Sigma chemicals, St Louis USA) dissolved in $0.1 \mathrm{M}$ fresh cold citrate buffer at a $\mathrm{pH}$ of 4.5 into 12 hours overnight fasted rats (Burcelin et al., 1995). After 3 days, fasting blood sugar levels were monitored with a glucometer (Accu check active, Roche Diagnostics $\mathrm{GmbH}$, Germany) and the rats having fasting blood glucose levels more than 200mg/dl were isolated, classified diabetic and used for experimentation.
Experimental design: The grouping and treatment given to the rats in each groups are as follows;

Group A: Designated as NDC consisted of nondiabetic control rats administered $1 \mathrm{ml}$ of distilled water.

Group B: Designated as DC consisted of diabetic control rats administered $1 \mathrm{ml}$ of streptozotocin.

Group C: Designated as DO consisted of diabetic rats administered $1 \mathrm{ml}$ of orthodox drug (insulin).

Group D: Designated as DAM1 consisted of diabetic rats administered 100mg of Afromomum meleguata seeds extract.

Group E: Designated as DAM2 consisted of diabetic rats administered 150mg of Afromomum meleguata seeds extract.

Group F: Designated as DAM3 consisted of diabetic rats administered 300mg of Afromomum meleguata seeds extract.

Sacrifice of the animals: At the end of the experimental period, rats in each study group were fasted overnight and sacrificed under anesthesia by cervical dislocation.

Serum collection and organ extraction: After the rats have been sacrificed, $2-4 \mathrm{ml}$ of blood was collected from each rat and placed in specific sterile bottles (plain bottles for enzyme analysis and EDTA bottles for haematological indices). For enzyme analysis, the blood was allowed to stand for 30 minutes to clot and then centrifuge at 40009 for 15 minutes. The supernant, which is the serum, was carefully decanted and was kept at $4^{\circ} \mathrm{C}$ for further analysis.

\section{Determination of l-alanine amino-} transferase (EC. 2.6.1.2) activity: L-alanine aminotransferase (ALT) activity was estimated by the method of Reitman and Frankel (1957). The method measures spectrophotometrically the intensity of the coloured hydrazine formed from the reaction of pyruvate with 2,4-dinitrophenyl hydrazine at $546 \mathrm{~nm}$. 
Determination of l-aspartate aminotransferase (EC. 2.6.1.2) activity: L-aspartate aminotransferase (AST) activity was estimated by the method of Reitman and Frankel (1957). The method measures spectrophotometrically the intensity of the coloured hydrazine formed from the reaction of pyruvate with 2,4-dinitrophenyl hydrazine at $546 \mathrm{~nm}$.

Principle: The assay is based on the following reaction of the enzyme;

L-aspartate $+\alpha$-ketoglutarate $\rightleftharpoons$ Oxaloacetate + L-glutamate

Oxaloacetate produced by transamination activities of AST is spontaneously decarboxylated to pyruvate which then react with 2,4dinitrophenylhydrazine. The intensity of the red colour formed is a measure of transaminase activity. The reactions stopped by addition of $2.5 \mathrm{ml}$ $0.1 \mathrm{NaOH}$ solution.

Determination of alkaline phosphatase activity: Alkaline phosphatase activity was assayed according to the method described by Bassey et al. (1946) and modified by Wright and Plummer (1974).

Determination of albumin: The method was described by Plummer (1979) was used to determine the albumin concentration.

\section{Lipid profile}

Total cholesterol determination: Cholesterol was measured enzymatically, in serum or plasma, in a series of coupled reactions that hydrolyze cholesteryl esters and oxidize the $3-\mathrm{OH}$ group of cholesterol. One of the reaction by products, $\mathrm{H}_{2} \mathrm{O}_{2}$ is quantitatively measure in a peroxidase catalyzed reaction that produces a colour. Absorbance is measured at 50onm. The colour intensity is proportional to cholesterol concentration. The reaction sequence is as follows:

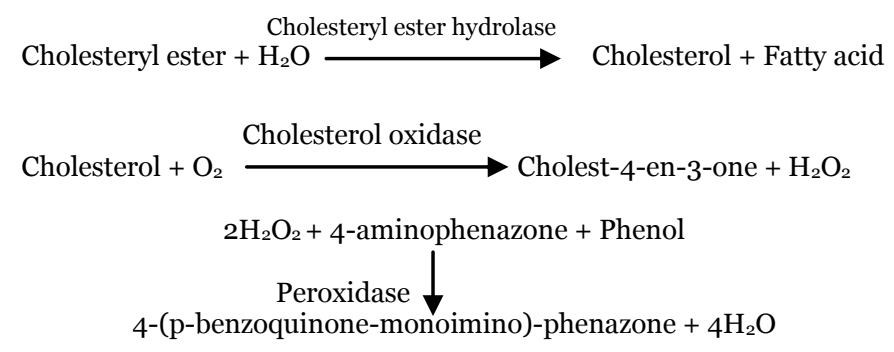

\section{Triacylglycerol (TAG) determination}

Triacylglycerol was measured enzymatically in serum or plasma using a series of coupled reactions in which triglycerides are hydrolyzed to produced glycerol. Glycerol is then oxidized using glycerol oxidase and $\mathrm{H}_{2} \mathrm{O}_{2}$, one of the reaction products, is measured as described above for cholesterol. Absorbance is measured at 500nm. The reaction sequence is as follows;

$$
\begin{aligned}
& \text { Triglycerides }+3 \mathrm{H}_{2} \mathrm{O} \stackrel{\text { Lipase }}{\longrightarrow} \text { Glycerol + Fatty acids } \\
& \text { Glycerol + ATP } \stackrel{\text { Glycerokinase }}{\longrightarrow} \text { Glycerol-3-phosphate + ADP } \\
& \text { Glycerophosphate oxidase } \\
& \text { 4-(p-benzoquinone-monoimino)-phenazone }+2 \mathrm{H}_{2} \mathrm{O}+\mathrm{HCl}
\end{aligned}
$$

High density cholesterol determination: HDL was measured directly in serum. The basic principle of the method is as follows; The apo $\beta$ containing lipoproteins in the specimen reacted with a blocking reagent that renders them nonreactive with the enzymatic cholesterol reagent under conditions of the assay. The apo $\beta$ containing lipoproteins are thus effectively excluded from the assay and only HDL-cholesterol is detected under the assay conditions and these reactions were as shown below;
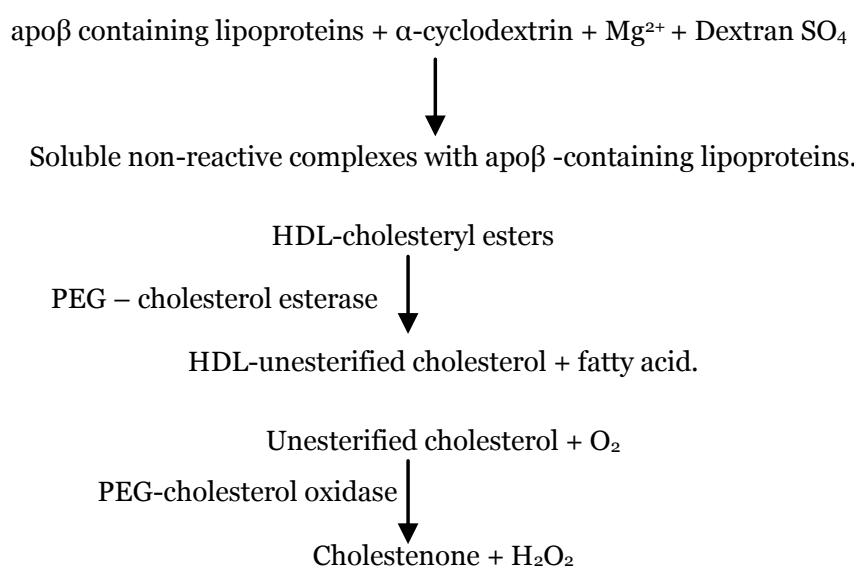


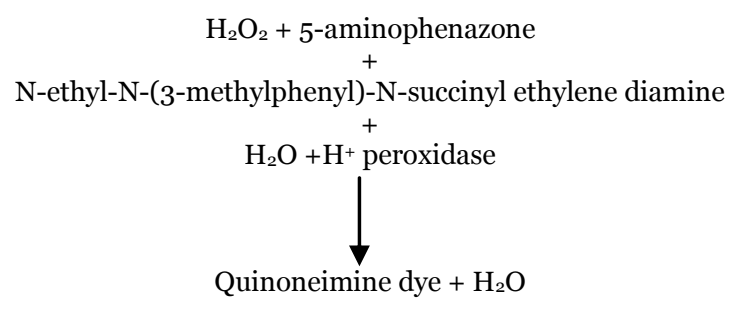

Absorbance was measured at 6oonm.

Low density cholesterol determination: Most of the circulating cholesterol is found in three major lipoprotein fractions, very low density lipoproteins (VLDL), low density lipoproteins (LDL), high density cholesterol (HDL).

$[$ Total Cholesterol $]=[$ VLDL-cholesterol $]+[$ LDL-cholesterol $]+[$ HDL-cholesterol $]$

LDL-cholesterol is calculated from measured values of total cholesterol, triglycerides and HDLcholesterol according to the relationship:

$[$ LDL-cholesterol $]=[$ Total Cholesterol $]-[$ HDL-cholesterol $]-[$ TG $] / 5$

where $[\mathrm{TG}] / 5$ is an estimate of VLDL-cholesterol and all values are expressed in $\mathrm{mg} / \mathrm{dL}$.

LDL carries most of the circulating cholesterol in man and when elevated contributes to the development of coronary atherosclerosis. LDLcholesterol is measured to assess risk for CHD and to follow the progress of patients being treated to lower LDL-cholesterol concentrations. Desirable levels of LDL-cholesterol are those below 130mg/dL in adults and $110 \mathrm{mg} / \mathrm{dL}$ in children. In NHANES 2001-2002, LDL-cholesterol will be reported only for fasting participants $>$ 5years of age.

\section{Haematological investigation}

Haemoglobin estimation method: Cyanmethaemoglobin (Baker and Silverton, 2003).

\section{Packed cell volume}

Method: Microhaematocrit (Baker and Silverton, 2003)

Materials: Capillary tube, haematocrit centrifuge, haematocrit reader, plasticine

Principle: Anticoagulant blood in a glass capillary of specified length, bore size and wall thickness is centrifuged at $12,000 \mathrm{rpm}$ for $5 \mathrm{~min}$ to obtain a constant packing of the red blood cells while the plasma remains above the cells.

\section{Total white blood cell count}

\section{Differential white cell count: Platelet count}

Principle: Ammonium oxalate lyses red cells and preserves platelets which are retractile particles.

\section{Statistical analysis}

The data will be expressed as Mean value \pm S.E.M (Standard error of the mean). All results will be mean of 8 data samples and the statistical analysis will be carried out using students't-test. The values will be considered at probability level of $\mathrm{P}<0.05$. All the values of $\mathrm{P}<0.05$ will be considered statistically significant.

Results: The results of the present study are presented in Table 1 and Figs. 1-7.

Table 1. Result of phytochemical screening Afromomum meleguata seeds extract.

\begin{tabular}{llc}
\hline S/No. & Phytochemical Components & Afromomum meleguata extract \\
\hline 1. & Alkaloids & + \\
2. & Flavonoids & + \\
3. & Steroids & + \\
4. & Saponins & + \\
5. & Tannins & + \\
6. & Anthraquinones & - \\
7. & Phenolic & - \\
8. & Terpenoids & + \\
9. & Quinones & - \\
10. & Oxalate & - \\
11. & Carderolides & - \\
12. & Cardiac Glycosides & + \\
\hline
\end{tabular}

+ Present; - Absent 


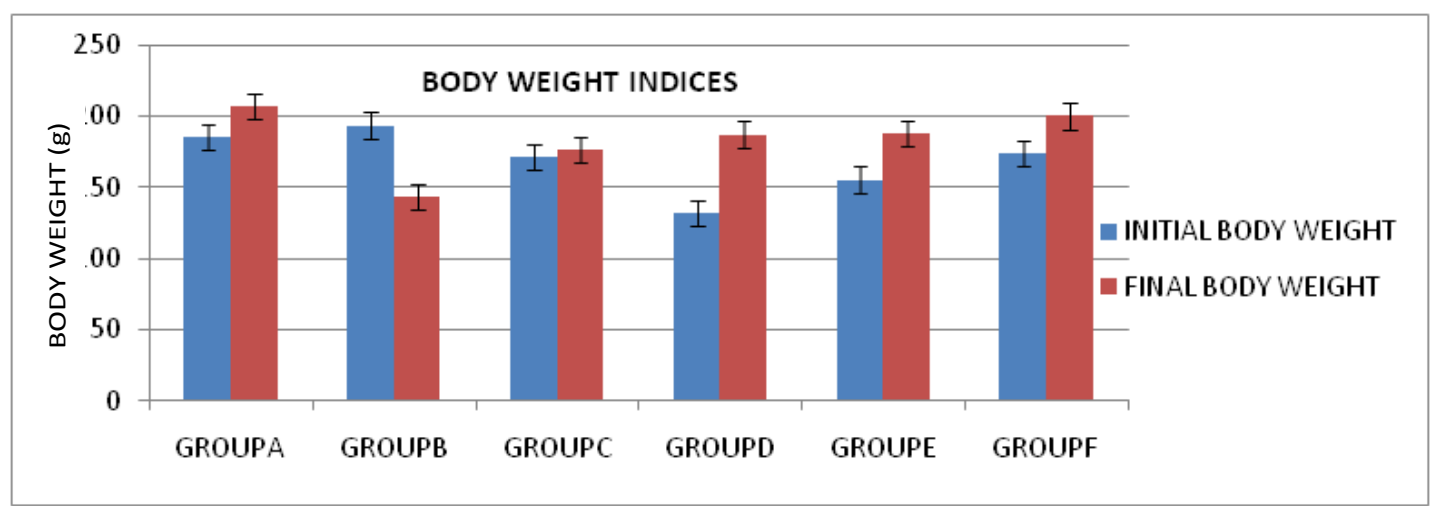

Fig. 1: Percentage Change in weight of rats on day o and day 14 of STZ-induced diabetic rats treated with ethanolic extract of Afromomum meleguata. Values are expressed in Mean \pm SEM of 8 independent determinants.

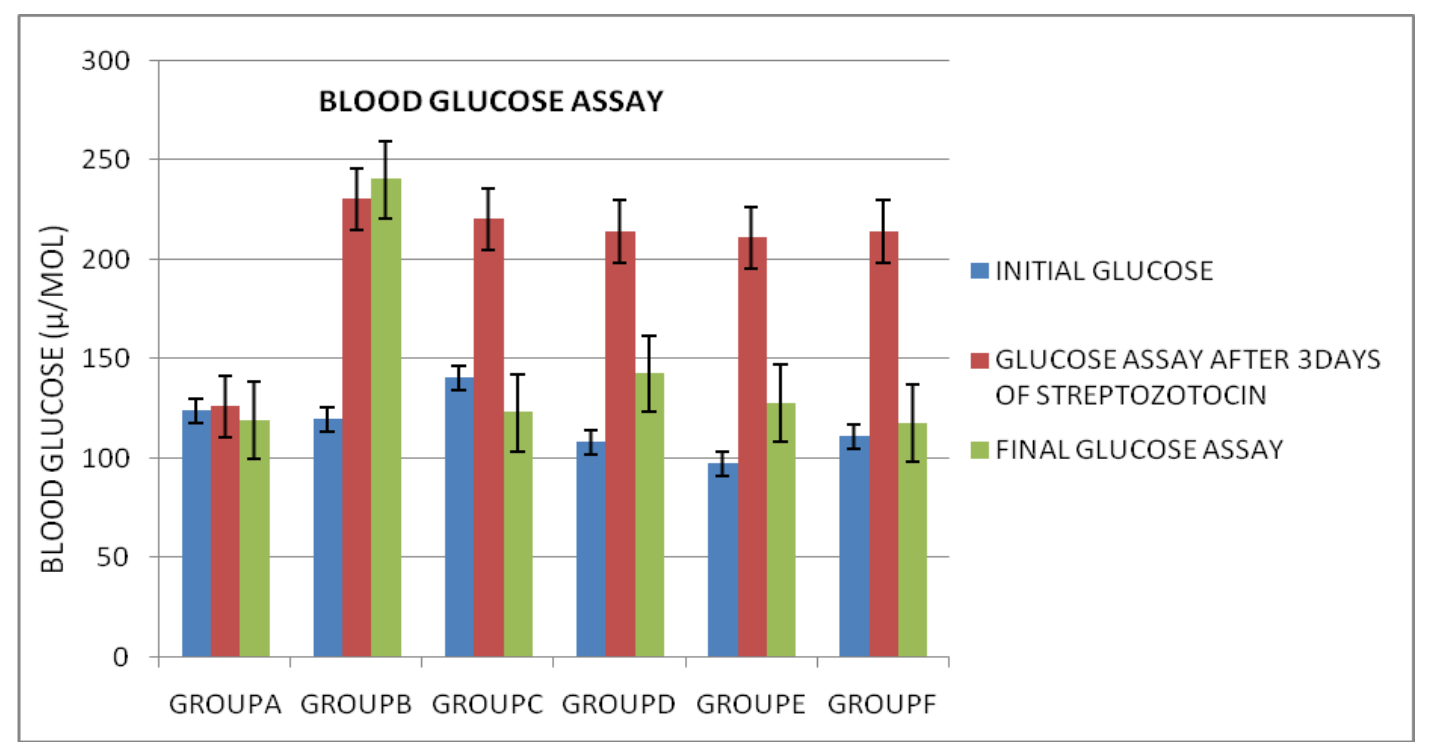

Fig. 2: Shows reduction in blood glucose between day o and day 14 after STZ-induced diabetic rats was treated with ethanolic seeds extract of Afromomum meleguata. Values are expressed in Mean \pm SEM of 8 independent determinants.

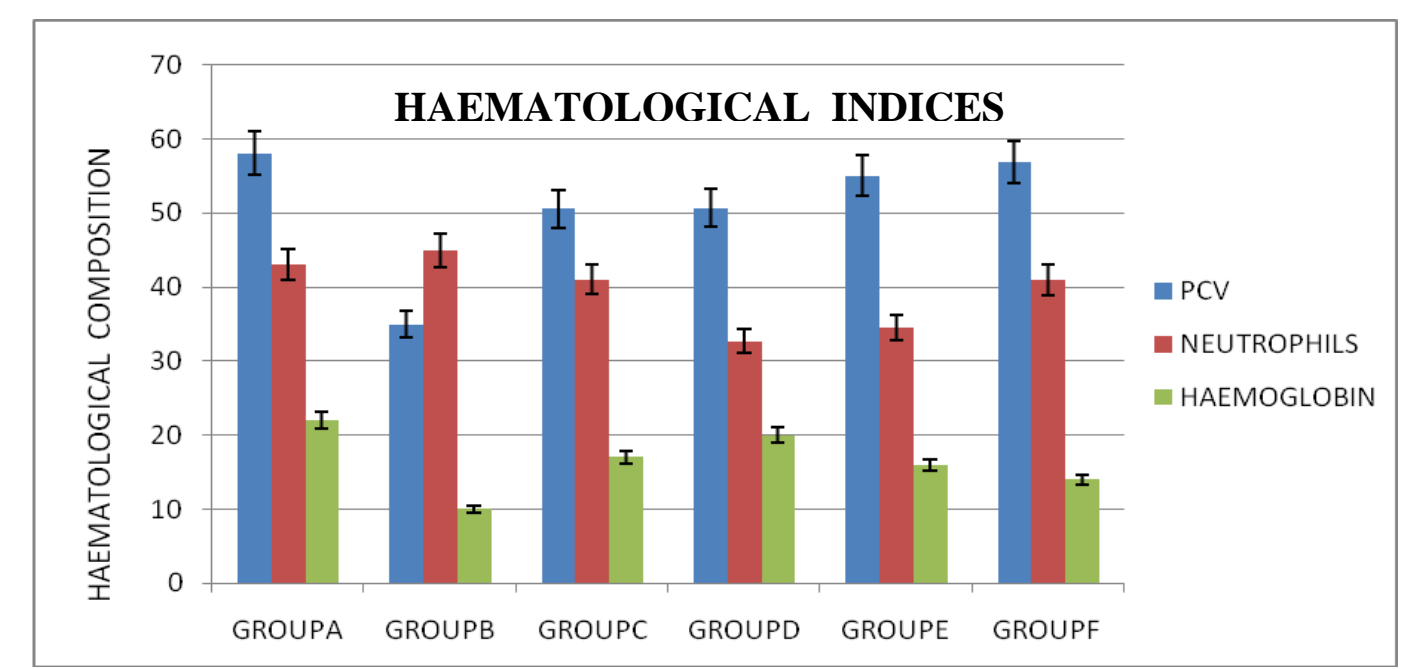

Fig. 3: Effect of ethanolic seeds extract of Afromomum meleguata on concentration of PCV, neutrophils and heamoglobin. Values are expressed in Mean \pm SEM of 8 independent determinants. 


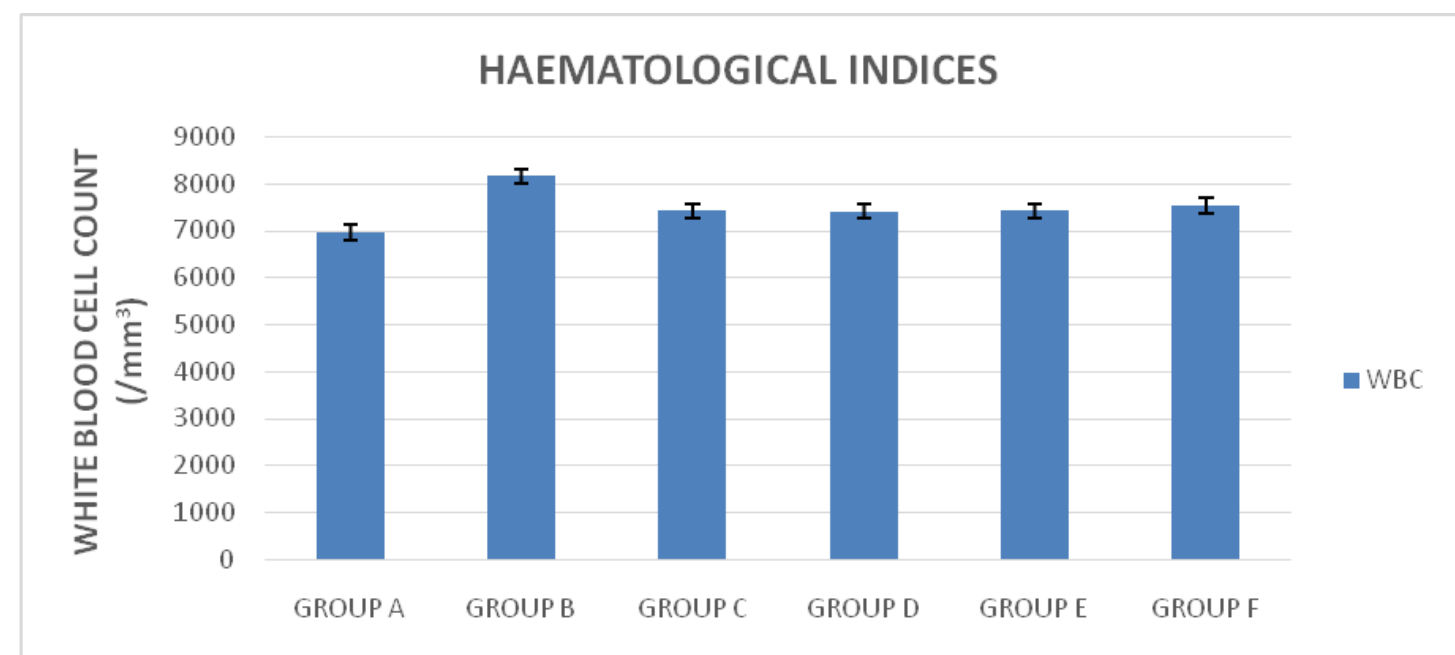

Fig. 4: Effect of ethanolic seed extract of Afromomum meleguata on concentration of WBC in streptozotocin-induced diabetic rats. Values are represented as Mean SEM of 8 independent determinants.

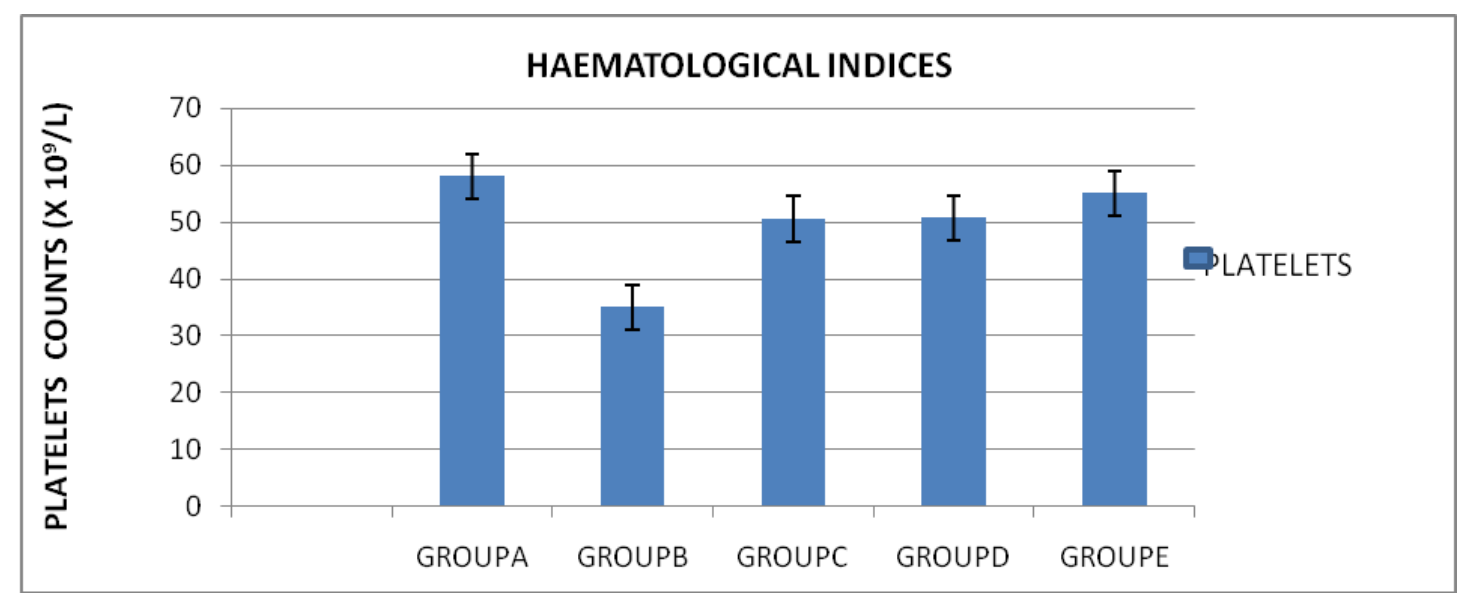

Fig. 5: Effect of ethanolic seeds extract of Afromomum meleguata on Concentration of platelets in streptozotocininduced diabetic rats. Values are represented as Means \pm SEM of 8 independent determinants

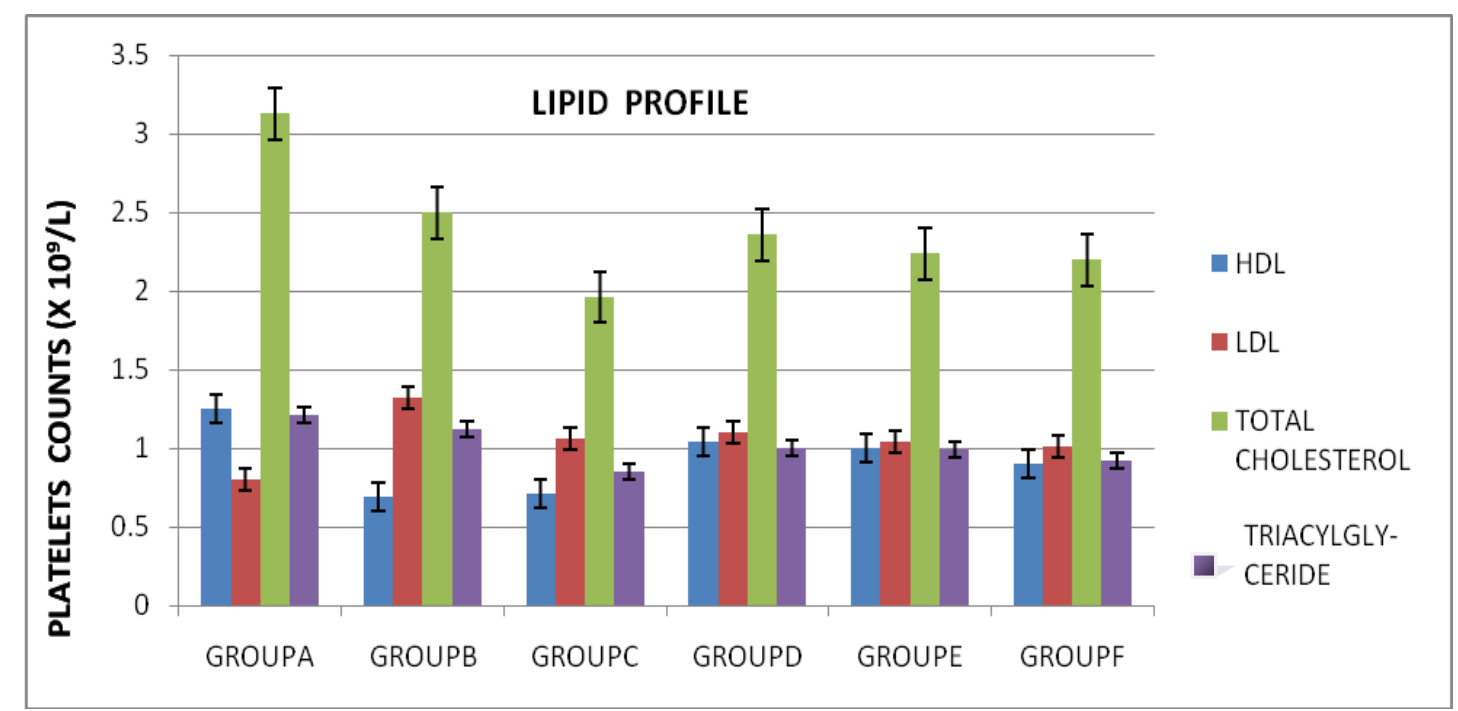

Fig. 6: Effect of ethanolic seeds extract of Afromomum meleguata on lipid profile in streptozotocin-induced diabetic rats. Values are represented as Means \pm SEM of 8 independent determinants. 


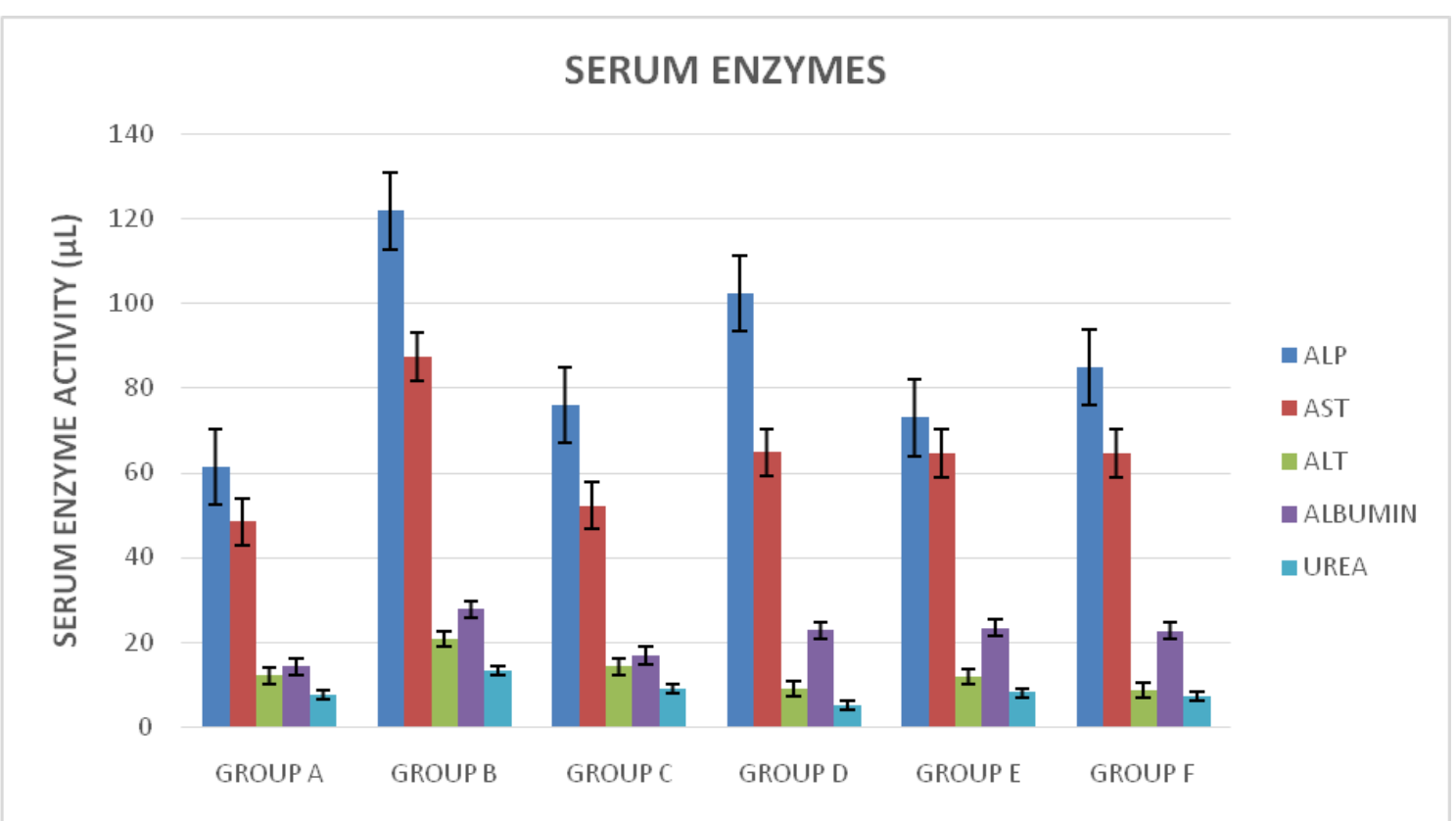

Fig. 7: Effect of seeds extract of Afromomum meleguata on serum enzymes in streptozotocin-induced diabetic rats. Values are represented as Means \pm SEM of 8 independent determinants.

\section{Discussion}

According to the literature, the pharmacological activity and the phytochemical compositions confirm the traditional use of some antidiabetic plants. It is noted that the antidiabetic effect results from several chemical elements: alkaloids, sterols, essential oils and triterpenes. The results of the phytochemical investigations on the plants under study confirmed the traditional use of these antidiabetic plants. The pharmacology of these Afromomum meleguata seeds can therefore be linked to the presence of alkaloids, triterpenoids and sterols phytoconstituents in the plants.

The oral dose of the ethanolic seeds extract of Afromomum melegueta, a dose related decrease in blood glucose level were observed for both the diabetic and non-diabetic rats compared to their control counterparts $(\mathrm{P}<0.05)$. The Afromomum melegueta ethanolic extract resulted in significant decrease $(\mathrm{P}<0.05)$ in the blood glucose levels in the diabetic groups especially at highest dose of 300 $\mathrm{mg} / \mathrm{kg}$. Although similar effects were also recorded in the non-diabetic groups significant reductions were observed more on streptozotocintreated diabetic rats than non-diabetic rats. The results are similar to that obtained in a recent study by llic et al. in which the effect of ethanol extract of the seeds of Afromomum melegueta caused reduction in blood glucose level in diabetic rats. The lowest dose of our seed extract produced non-statistically significant decrease in blood glucose level $(\mathrm{P}>0.05)$ in the diabetic rats. This may be due to the low concentration of the active phytochemicals in the extract.

In the haematological studies, the diabetic control showed marked reduction in PCV and Hb agreeing with existing literature that anaemia is a common pathophysiology associated with diabetes mellitus (Akindele et al., 2012; Colak, 2012). Afromomum meleguata however elevated these parameters including the platelets which suggest that the extract has anti-anaemic property which may be due to its high iron content (Saliu et al., 2012) and the ability to improve bone marrow functions, a major site for erythropoiesis (Orhue et al., 2008).

It has been demonstrated that insulin deficiency in diabetes mellitus leads to accumulation of lipids such as total cholesterol and TGs in diabetic patients (Kameswararao et al., 2003). In uncontrolled diabetes mellitus, increase in total cholesterol, triglyceride, LDL and VLDL cholesterol with decrease in HDL-cholesterol which contributes to coronary artery disease has been observed (Arvind et al., 2002). The STZinduced diabetic rats showed increase in the cholesterol, LDL cholesterol and triglyceride 
concentrations. Administration of our extracts reduced the total cholesterol, triglyceride, LDL cholesterol and improved HDL cholesterol level which is in agreement with the works of Twaij and Al-Badr (1988). This effect is of significant value since serum lipids profile is an important risk factor to many diseases like diabetes, hypertension, etc. A reduction in triacylglycerol level may be due to decreased lipogenesis, increased lipolytic activity by inhibition of hormone-sensitive lipase or the lipogenic enzymes or activation of lipoprotein lipase as have been proposed for some anti-diabetic plants exhibiting hypoglycemic activity as observed in this present study.

The mechanism by which the serum aspartate aminotransferase (AST), alanine aminotransferase (ALT), and alkaline phosphatase (ALP) are elevated in diabetic control may involve liberation of these enzymes owing to oxidative stress or the formation of progressive glycosylation end product. Treatment of diabetic rats with Afromomum meleguata extract significantly decreased the activity of these enzymes as compared to untreated diabetic rats, indicated the preventing diabetic complications. In the present study, there was an elevation in urea nitrogen in the streptozotocin- induced diabetic rats treated with the oral administration of Afromomium meleguata extracts supplementation (Mori et al., 2003). In heamatological indices, there was a significant decrease in groups treated with Afromomium meleguata showing better response with respect to the group $B$. when compared with group A.

\section{Conclusion}

In conclusion, results obtained from the studies reveal the hypoglycaemic and hypolipidemic properties of Afromomum meleguata and suggest that the extract is a safe and potent agent capable of bringing to normal, glucose, haematological and lipid abnormalities associated with diabetes mellitus and as such could be used in the management of the diabetes disease. The result of the present study showed that Afromomum meleguata brings back the blood glucose and body weight to normal in diabetes-induced rats. It may prevent the hepatic injury and revamp the pancreas while suppressing the oxidative stress associated with diabetes.

\section{Conflict of interest statement}

Authors declare that they have no conflict of interest.

\section{References}

Adams, D. D., 2008. Autoimmune destruction of pericytes as the cause of diabetic retinopathy. Clin. Ophthalmol. 2 (2), 295-298.

Akindele, O.A., Babatunde, A.I., Chinedu, F.M., Samuel, O.A., Oluwasola, C.A., Oluseyi, A.A., (2012). Rat model of food induced non-obesetype 2 diabetes mellitus; comparative pathophysology and histopathology. Int. J. Physiol. Pathophysiol. Pharmacol. 4(1), 51-58.

Alvind, K., Dradeepa, R., Deepa, S., Mohan,V., 2002. Diabetes and coronary artery diseases. Indian Med. Res. 16(6), 163-176.

Baker, R., Silverton, T., 2003. Blood: Principles and Practice of Haematology. Lippincott Williams and Wilkins, 4(2), 183-189.

Bassey, M., Udagawa, N., Fukasawa, K., Hiraoka, B.Y., Mogi, M., 1946. Inorganic pyrophosphatase activity of purified bovine pulp alkaline phosphatase at physiological pH. J. Dent. Res. 65 (2), 125-127.

Bent, S., Ko, R., 2004. Community used herbal medicines in the United States: A Review. Am. J. Med. 116(7), 478-485.

Burcelin, P. B., Kaplowitz, N., Slattery, J. T., 1995. Aminotransferase elevations in healthy adults receiving 4 grams of acetaminophen daily: a randomized controlled trial. J. Amer. Med. Assoc. 296 (1), 87-93.

Colak, S., GeyiKoghu, F., Aslan, A., Deniz, G. Y., 2012. Effects of lichen extracts on haematological parameters of rats with experimental insulin-dependent diabetes mellitus. Toxicol. Ind. Health. 5(2), 57-64.

Kafaru, E., 1985. Herbal Remedies: The Guardian. Guardian Newspaper Ltd, Rutan House, solo, Lagos. 22(3), 211-217.

Kameswararao, B., Kesavulu, M.M., Apparao, C., 2003. Evaluation of antidiabetic effect of Afromomum meleguata in induced streptozotocin-diabetic rats. Filoterapia. 74(12), 7-13.

Mori, D.M., Baviera, A.M., Oliveira Ramalho, L.T.D., Vendramini, R.C., Brunetti, I.T., Pepato, M.T., 2003. Temporal response pattern of biochemical analytes in experimental 
diabetes. Biotechnol. Appl. Biochem. 38(7), 183-191.

Olapode, E. O., 2002. The herbs for good health Narl Specialist Clinic, Ibadan, Nigeria. 13(4), 342-344.

Orhue, E. G., Idu, M., Atamari, J. E., Ebite, L. E., 2008. Haematological and histopathological studies of Afromomum meleguata on wister rats. Asian J. Biol. Sci. 192(8), 84-89.

Reitman, F. J., Frankel, E. T., 1957. Purification and characterization of aspartate aminotransferase from the halophile archaebacterium Haloferax mediterranei. Biochem. J. 278 (1), 149-154.

Saliu, J. A., Elekofehinti, O. O., Komolafe, K., Oboh, G., 2012. Effects of some green leafy vegetables on the haematological parameters of diabetic rats. J. Natural Prod. Plant Resour. 2(4), 482-485.

Sharma, C., 1986. Material Medica and Medicine New Delli, India. pp.21-24.
Sher, A., 2009. Antimicrobial activity of natural products from medicinal plants. Gomal J. Med. Sci. 7(1), 72-78.

Sofowora, A., 1982. Medicinal Plants and Traditional Medicine in Africa. John Wiley and Sons Ltd.

Tarnow, L., Groop, P. H., Hadjadj, S., Kazeem, G., Cambien, F., Marre, M., Forsblom, C., Parving, H. H., 2008. European approach for the genetics of diabetic complications. Nephrol. Dial. Transplant. 23 (1), 161-168.

Twaij, H. A. A., Al-Badr, A., 1988. Hypoglycemic activity of Afromomum meleguata. J. Ethmopharmacol. 24, 123-126.

UNESCO, 1976. The Saturday Newspaper, Dec.13, 1976.

Wright, A., Plummer, C., 1974. A fine-structure genetic and chemical study of the enzyme alkaline phosphatase of $E$. coli. I. Purification and characterization of alkaline phosphatase. Biochem. Biophys. Acta. 38(5), 470-83.

\section{How to cite this article:}

Ukpanukpong, R. U., Otu, D. O., Olarinde, O. E., Fafioye, R. O., Ukwuondi, B. E., Igbineweka, P. O., 2019. Antidiabetic effect of Afromomum meleguata ethanolic seed extract on streptozotocin induced diabetic Wistar rats. Int. J. Curr. Res. Biosci. Plant Biol. 6(1), 19-28.

doi: https://doi.org/10.20546/ijcrbp.2019.601.004 